\title{
Taming Wild Ducks: Cultural Impacts of Incubation Integration in a Very Large Technology Corporation
}

\author{
Michael Featherstone ${ }^{1}$, Mary Angela Duffy², Michael Marker ${ }^{1}$ \\ ${ }^{1}$ School of Business and Industry, Jacksonville State University, Alabama, United States \\ ${ }^{2}$ T. Rowe Price, Baltimore, Maryland, United States \\ Email: feather@jsu.edu
}

\begin{abstract}
This is a case study that explores the difficult transition that the IBM e-Business Innovation Center in Atlanta experienced when it was finally fully integrated into IBM's Global Services Division. Although there has been much conjecture as to why this fusion failed, this paper explores lack of cultural fit between IBM and its fledgling Innovation Centers as the primary factor in their demise. Though the article examines an event which happened nearly twenty years ago, it offers a unique insight into a thoroughly current phenomenon, corporate sponsored entrepreneurship. Much of the information for this case was gleaned through interviews with participants in the event.
\end{abstract}

Keywords: Corporate culture, corporate entrepreneurship, business incubation, skunk works, business start-ups.

\section{$1 \quad$ Introduction and Background}

"I'm convinced that every business needs its wild ducks. At IBM we try not to tame them." Thomas Watson

This case study exams two aspects of current interest to researchers and college instructors, corporate entrepreneurship and corporate culture. Corporate entrepreneurship is defined as "a process that goes on inside an existing firm and that may lead to new business ventures, the development of new products, services or processes and the renewal of strategies and competitive postures. As such, it can be seen as the sum of a company's innovation, venturing and renewal efforts" [1].

Corporate culture refers to the beliefs and behaviors that determine how a company's employees and management interact and handle outside business transactions. Often, corporate culture is implied, not expressly defined, and develops organically over time from the cumulative traits of the people the company hires. A company's culture will be reflected in its dress code, business hours, office setup, employee benefits, turnover, hiring decisions, treatment of clients, client satisfaction and every other aspect of operations [2]. "Whether written as a mission statement, spoken or merely understood, corporate culture describes and governs the ways a company's owners and employees think, feel and act" [3]. Louis V. Gerstner, former IBM Chief Executive Officer describes corporate culture as "the cumulative effect of all of these processes: compensation, performance measurement, recognition, etc." [4].

The concept of incubating start-up entities within large corporations is not new. However, due in part to the increasing speed of change in technology, the concept is more prevalent today. "For large companies, creating new businesses is the challenge of the day. After years of downsizing and cost cutting, corporations have realized that they can't shrink their way to success. They've also found that they can't grow rapidly by tweaking existing offerings, taking over rivals, or moving into developing countries" [5]. Business incubators aim to promote creation of enterprises and inculcate entrepreneurship by utilizing the ability and creativity of the incubatees [6].

The impact of culture on corporate nurturing of new businesses is lightly covered in the literature. "From our review, it is clear that research has just begun to scratch the surface of the incubatorincubation phenomenon. While much attention has been devoted to the description of incubator facilities, less attention has been focused on the incubatees, the innovations they seek to diffuse, and the incubation outcomes that have been achieved" [7]. 
This case expands on research by Garvin and Levesque. They identify the issue as ... "the challenges [of integration] come later, when it's necessary to integrate fledgling businesses with the mainstream. Because centralized new-venture groups magnify the clash between the old and the new cultures, suspicion and fractious relationships are common, as are power struggles between new-business managers and division leaders. Over time, integration becomes more problematic, and companies must either spin off the new businesses or shut them down [8].

To determine the cultural differences discussed later in the case, an Organizational Culture Inventory tool was utilized. This tool was selected because it...

provides a reliable, valid, and true measure of culture clearly distinguishing culture and climate as distinct yet interrelated organizational variables, and meets rigorous academic and psychometric standards with results reported in numerous journals and the Handbook of Organizational Culture \& Climate [9].

In Atlanta in September 1994, IBM launched a new group, ostensibly to explore revenue prospects for an emerging "Video on Demand" (VoD) market. However, it became clear that an even greater opportunity might exist in the business environment of the nascent World Wide Web. True to their entrepreneurial instincts, the small VoD group quickly morphed into an Atlanta web design center which ultimately emerged as the first in a series of e-business "Innovation Centers".

The Innovation Centers evolved from the Design Studio, the initiative begun in Atlanta in 1994. Until this point, the Internet had been almost exclusively the realm of academe, research facilities and, to a lesser degree, government. But it was evident to the Design Studio founders that its potential for business applications was limitless. This group was among the first of what became identified as "A few visionary individuals at IBM, who discovered the Internet as a potential source of future revenues, brought about the major change that took place in the mid-1990s. This small group of believers developed an Internet strategy for the corporation as a whole" [11].

In late 1994, the Studio manager, Peter Blakeney, suggested that the Design Studio do an Internet project. The differentiator however, was that instead of just being able to obtain information, consumers would be able to buy merchandise via the web-site. In the fall of 1994, the Design Studio began work on a web-site for the National Hockey League to be completed in time for the Stanley Cup Playoffs to be held early in 1995. The project was completed on time and was a huge success as fans flocked to the web-site to purchase their teams' merchandise. To promote the web-site and IBM's ebusiness capability, this project was featured in one of IBM's award winning e-business ads in early 1996. The ad portrayed three old timers from the league sitting in a bar and reminiscing on how long it took them to get their hockey jerseys and what they meant to them. A teenager, who overhears their conversation, butts in and tells them it took him three minutes to order his on line and it cost $\$ 35$ - 'it was easy!' The ad ends with the frustrated old-timers chasing the cocky teenager out of the bar.

The success of that project won the Design Studio both acclaim and credibility. By 1998, it had become the biggest web design and build workshop in the world, winning IBM the title 'The Biggest Dot Com of Them All'. For an interview with Wall Street analysts in May 1998, Lou Gerstner had an assistant pull the financial reports on 25 of the 'real Internet standard bearers' - companies like Yahoo!, America Online, Amazon.com, eBay and e-Trade. In 1998, those companies generated combined revenues of about $\$ 5$ billion, and lost $\$ 1$ billion. Yet the market value of the Internet 25 together was $50 \%$ greater than that of IBM. In a speech to Wall Street, the CEO noted that IBM was already generating more e-business revenue and certainly more profit than all of the top Internet companies combined [12]. At that time, $25 \%$ of IBM's revenue, some $\$ 20$ billion, was driven by e-business demand. About $75 \%$ of IBM's e-business revenue came from sales of Net technology, software and services - a fast growth, high margin business - unlike the older technologies for which IBM was so well known. These incredible business results were due in a large part to the leading edge business solutions developed by the Design Studio. From mid-1996 through mid-1999, the Design Studio handled 18,000 Internet jobs for customers, from shaping an Internet strategy to Web page design to hosting entire online storefronts.

In 1999, in an effort to capitalize on IBM's lead in the e-business space and gain competitive advantage over competitors, IBM reorganized, centralizing many operations and consolidating many lines of business. During this period, IBM began bringing some 'wild ducks' in-house. Many independent divisions, like the Design Studio, became part of IBM's Global Services, the service delivery and consulting wing of IBM. The rationale for doing this made sense from a business standpoint. By properly aligning resources and working as one team, IBM had the ability to deliver end to end solutions 
to customers, something no competitor could do. If done successfully, this strategy could result in an incredible payoff for IBM.

As part of this strategy, the Design Studio became the prototype for what would come to be called the IBM e-Business Innovation Center and its business model was replicated in key cities across the United States. New Centers were launched in Chicago, Dallas, Washington, D.C., Boston, and Los Angeles, with Centers planned in Germany, the U.K., Italy and France within six months. The Innovation Centers took the creative philosophy espoused by the Design Studio to another level. They provided a creative hub where customers would work collaboratively with industry experts to design solutions to transform their businesses into e-businesses via high-quality, strategic Web solutions [13]. The Innovation Centers brought their solutions to market quickly, contributing to their enormous success.

In the period immediately after the merger into IBM Global Services, the Innovation Centers continued to produce stellar results for IBM and its customers. IBM's official archive notes:

"For the fourth consecutive year, IBM and The All England Lawn Tennis Club collaborate to produce the official Wimbleton (sic) Web site, which records over 224 million server hits during the 1998 Championships. The official Web site of the 1998 French Open tennis championships, designed and hosted by IBM, records 146.9 million server hits during the two-week tournament in June. Then in September, the official 1998 U.S Open Web site, powered by IBM for U.S. Tennis Association, records 382 million hits during the two-week tournament." [14].

However, by mid-2000, signs of an economic downturn became apparent. IBM reacted to the tightening economy with cost cutting measures. Increasingly, all divisions had less freedom to control their business, and the Innovation Centers came under close scrutiny. Dramatic changes ensued throughout the organization as IBM imposed its bureaucratic internal processes upon everyone. This caused the Innovation Centers much discomfort because, until now, they had been immune to IBM's control processes. As the economy got weaker and IBM's control on the Innovation Centers tightened further. The result was mass attrition from the Centers because of the lack of fit between the Innovation Centers and IBM. In mid-2001, IBM closed all but one of its Innovation Centers.

\section{Role of Culture}

Louis V. Gerstner joined IBM in 1993 as its first 'outside' CEO. His mission was to turn around what was then viewed as a now fast fading technology company and by most accounts he accomplished his mission. Gerstner's tenure saw stock prices increase $800 \%$ and he was credited with transforming IBM's 'hidebound' culture [15].

To position IBM as an e-business company, Gerstner set out to create an Internet culture. Peter Blakeney had already established a prototype for this cultural transition at the Atlanta Design Studio, where employees often brought their pets to work, availed themselves of the on-site masseuses, had ping-pong tables that doubled up as conference tables and played billiards in an upstairs room to clear their heads from long hours of toil on their Macintosh computers. It was common to see employees sporting goatees and multiple body piercings. To attract the cool, younger, Internet savvy people, Gerstner had to break with the whole IBM culture. To promote the creative atmosphere, the dress code also was very casual, with t-shirts and blue jeans and sneakers as common business wardrobes [12].

IBM spent $\$ 100$ million to transform the Design Studio into the first IBM e-Business Innovation Center. The physical office was located in an affluent suburb of Atlanta in an I.M. Pei building faced in black marble and lavishly appointed inside. Leather furniture, brightly colored rugs and original artwork graced the common spaces in the center. Work-stations featured cutting edge design and ergonomic chairs and lighting. Music created an upbeat atmosphere. Innovation Center employees had dedicated office space and customers came to the Centers to mingle with the Internet experts and to participate in technology demonstrations.

By contrast, traditional IBM sites are quiet, subdued and appointed in either beige or gray. Cube walls are traditionally high to ensure privacy for the benefit of the cube occupant and information he or she is handling. Dress codes in corporate IBM facilities are conservative business attire; mostly navy suits for both men and women. In the individual divisions, however, the culture is more relaxed. Employees wear casual clothes to work and depending on their role, they may work in teams, 
either at client sites or remotely via electronic means. Functions have their own dedicated spaces in most sites as do administrative support. Artwork mostly consists of pictures of IBM products or prototypes of the original equipment!

Despite obvious outward differences, cultural discord was minimal. When viewed in terms of the Organizational Culture Inventory [10, table 1], the culture of the Innovation Centers was north-oriented, meaning that the organization was people-oriented and sought to satisfy an individual's need for job satisfaction. In such an organization, people are empowered. More specifically, the Innovation Centers were achievement-oriented, self-actualizing, and humanistic-encouraging-oriented. Setting and achieving goals, serving customers well and solving problems creatively were highly valued. Employees were encouraged to take risks and think outside the box to solve customers' problems with the maximum creativity. Employees at the Innovation Center enjoyed their work, demonstrated by the early starts and the long hours people chose to work in pursuit of cutting edge solutions. The management style at the Innovation Centers was participative, relaxed and open. Solution teams were encouraged to play 'devil's advocate' as a strategy to ensure development of the best possible solution to a business problem.

These constructive styles were pervasive throughout IBM in the mid-90s. Although corporate IBM had a command and control structure in place, the company had moved away from its autocratic past by giving the divisions autonomy to engage in participative management and push decisions down to the sales and consulting teams. Significant rewards and recognition for achievement were commonplace. IBM spent lavishly on rewarding employees for teamwork, big wins in the marketplace and superior execution of leading edge customer solutions. So when the Atlanta Design Studio (later the Innovation Center) came into being, its cultural fit with IBM was a fairly strong one. Both organizations shared similar values and incentives were aligned to encourage creativity.

\section{$3 \quad$ Assessment of Fit}

According to Cooke and Lafferty, 'a snapshot of a successful company at any given point in time.... would show a strong external fit between the company and its environment [10]. From the inception of the Design Studio until its evolution into a chain of Innovation Centers in May 1998, the fit between IBM and this creative e-business was strong. Indeed, much of the success of the Innovation Centers could be attributed to the strong 'fit' between the Innovation Centers, IBM and the external business environment. From 1994 until 1999, the economy was robust and businesses were seeking creative ways to leverage strengths and develop competitive advantage. The Innovation Centers fulfilled this goal for IBM. By allowing the Innovation Centers to operate independently, IBM sheltered the centers from weighty, autocratic internal IBM processes, enabling the Innovation Centers to concentrate on meeting customers' needs by developing leading edge technologies.

During this period, both IBM and the Innovation Centers were Prospectors, firms that are first into a market or firms that anticipate market direction and help shape it. Problems with fit came in mid-2001, after the Innovation Centers were integrated into IBM's Global Services Division. Changes in the market caused IBM to act like a Defender [10], concentrating on offering a more restricted, stable line of products and eliminating unnecessary cost. During that time, the fit between the Innovation Centers, IBM and the external environment moved out of alignment. As the external environment changed, IBM reorganized to align with it. But the Innovation Centers were high cost propositions, and this put them in conflict with the Defender stance IBM was adopting. Because the Innovation Centers had developed a strong Prospector culture, they were unable to function in Defender mode. In the end, they fell victim to IBM's Defender cost cutting measures in an effort to improve bottom line results and keep the stock price high. In early 2001, IBM closed or radically reduced all the Innovation Centers except the Center for e-Government in Washington, D.C.

\section{$4 \quad$ Organizational Structure}

From a structural standpoint, the initial fit between IBM and the Innovation Centers was a good one [10, table 1]. IBM is organized in a divisional structure, with each division focused on a unique product mix. Divisions operated autonomously, each with its own profit and loss responsibility. The divisions have duplicate functions, but all consistently follow IBM Corporate guidelines. IBM Corporate defines 
the company's strategy and revenue targets, but the divisions are free to achieve those targets however they want. Incentives ensure performance and behaviors are aligned with strategic direction.

Consistent with IBM's Prospector past, the Design Studio, and later the Innovation Centers, was initially set up within IBM as a separate division with its own profit and loss responsibility, successfully sustaining itself since 1996. The Innovation Centers operated as an independent business although IBM was a source of work for them. Internally, each Center consisted of three main groups: the Producers, the Creatives and the Programmers. The producers were responsible for developing and selling business. The Creatives were responsible for figuring out the most innovative way to meet the client's needs and the Programmer was responsible for making the solution a reality. When IBM sponsored external events like the Olympics, tennis tournaments, Professional Golf Association and the Super Bowl, the Innovation Centers designed and built all the web-sites and oversaw all the related advertising. At $\$ 1$ million per web-site, the centers were highly profitable. Each center was a self-contained unit, with its own center manager, sales staff and support staff. Physically, the center strove for an open, relaxed atmosphere, with low walls and circular traffic patterns that encouraged collaboration.

This arrangement worked well from mid-1999 to mid-2000, when IBM reorganized and consolidated the Innovation Centers into IBM Global Services. But problems arose in mid-2001, when IBM reacted to signs of a slowing economy by imposing higher profit targets and stricter spending limits across the organization. IBM retreated from Prospector mode into Defender mode, resorting to managing by plan to weather the economic downturn. As the Innovation Centers began to lose their autonomy the lack of fit between the two organizations became evident. There was mass attrition from the Innovation Centers as IBM imposed its internal controls and culture on the Centers. Having grown up as an independent business with a participative management style, Innovation Center employees couldn't identify with the autocratic style IBM had reverted to and so they choose to go elsewhere. Because of its intense focus on controlling costs and eliminating waste, IBM smothered the creative culture of the Innovation Centers. Eventually, the head Innovation Center Manager was fired and replaced with an IBM heritage manager, who systematically dismantled the Innovation Centers.

\section{$5 \quad$ Product-Market Strategy}

In the early 90s, Both IBM and the Innovation Centers could be described as Prospectors, in that they both offered a broad changing product line. Famous for its extensive research and development, IBM constantly brought to market new and innovative products that would eventually become business staples: mainframes, personal computers, relational databases, point of sales systems, business intelligence systems, to name but a few. Keenly aware of and very responsive to market trends, IBM has been a leader in product innovation since the early 1900s.

The Innovation Centers were just another example of an innovative product by IBM. The Innovation Centers were Prospectors because they successfully charted new territory by developing a new channel for businesses to manage business, perform transactions and communicate with customers. Driven by emerging market needs and thinking beyond existing solutions, the Innovation Centers monitored and incorporated industry best practices to make IBM the leader in a new arena: e-business. The Centers operated in a very dynamic environment in which they worked with customers to define new, cutting edge technology, resulting in the Centers having their own broad, changing product line. The Innovation Centers were customer-focused, futuristic and entrepreneurial.

In mid-2000, IBM began to re-evaluate its strategy, which was by now out of alignment with the market. In an effort to realign strategy and itself with the marketplace, IBM eliminated offerings based on relative profitability. The Innovation Centers were forced to cut experimental programs, which to many of the Centers' employees stifled their creativity. With its new focus on narrow, stable product lines, IBM was forced to enact reductions in force, which had a de-motivating effect on remaining employees. During this period, the Innovation Centers lost some of its best employees.

\section{$6 \quad$ Research and Development}

IBM is known for its intense research and development, which has enabled it to be a Prospector since it was founded. The company even purchased its own market research firm, renamed Watson Research, to 
enable it to track market trends and maintain its lead on its competitors. IBM is famous for its innovative product design, which has enabled it to make IBM a household name.

The Innovation Centers maintained IBM's legacy in this regard by constantly performing their own market research, staying in close contact with customers who would define product requirements, and producing cutting edge solutions. Money was no object at the Innovation Centers, so a lot was spent just to stay ahead of the market.

IBM's adoption of a Defender stance in the mid-2000 caused a chasm to develop between IBM and the Innovation Centers. Budgets dedicated to market research were cut and layoffs ensued throughout IBM. This belt-tightening also applied to the Innovation Centers, where many employees felt their creative integrity was compromised by their inability to stay in lockstep with the market.

\section{$7 \quad$ Production}

IBM had learned a harsh lesson in the early 1990s when it almost went bankrupt because of its arrogance and internal-focus. In an effort to become customer-focused, IBM implemented flexible, adaptable processes, including a mobile workforce that could easily respond to market demand by being at the customer site and that would work closely with customers to solve their problems.

The Innovation Centers fit with this business model because they were entirely customerdriven. With the best equipment money could buy and the latest market intelligence, the Innovation Centers would keep the customer highly involved in solution development. If something wasn't in the customer's best interest, then it wasn't proposed to the customer as a potential solution.

When the economy began to show signs of decline, IBM reverted to its old ways by tightening control and focusing on cutting costs. Divisions were eliminated (including the Innovation Centers), plants were closed, production became unreliable and contracts were lost due to inability to deliver products and services.

\section{Control Processes}

IBM is at heart a command and control organization. But in the early 1990s, in an effort to be more responsive to the market, it decentralized many of the control processes it had in place. For example, each division was free to hire and fire as needed and procurement was done on an as-needed basis without the need for prior approval. The divisions managed by performance, recognizing and rewarding individuals and teams for their relative contribution to burgeoning market share.

The Innovation Centers are also managed by performance. Rewards and recognition at the Centers were legendary. Employees were highly motivated to give every project their best because they knew it was appreciated and it would be rewarded. But the atmosphere at the Innovation Centers was such that monetary rewards were not necessary to motivate employees. Because of its humanistic-encouraging culture, job satisfaction and commitment to the organization was so high that employees would look forward to coming to work at seven in the morning and they wouldn't leave until ten o'clock at night. As a result of the intense customer-focus, managers at the Center didn't place a great deal of emphasis on internal control processes.

When the Innovation Centers became part of IBM Global Services in 1999, the Innovation Center employees and managers experienced culture shock as they had IBM's bureaucratic control processes imposed upon them. In Defender mode, IBM centralized many control processes and imposed tight spending restrictions coupled with higher performance targets, which appeared harsh and unnecessary to most Innovation Center employees. Managers tried to insulate their employees from IBM's policies, but eventually they became exposed. Throughout the 1990s, the Innovation Centers operated totally separately from its parent, IBM, with its own systems, policies, and control processes. Suddenly, Innovation Center employees had to comply with IBM's policies and use the IBM systems for administration such as time and expense reporting, which caused an outcry.

Eventually, IBM performed an audit of the Innovation Centers' compliance with IBM's processes and they failed. Auditors investigated everything from compliance with expense limits to use of the internal procurement process, none of which the Innovation Centers used. The Centers were given six months to become compliant. Managers ran seminars to train employees on IBM's processes, but the perception 
among employees was that IBM was throwing its weight around and being unnecessarily heavy handed. Many Innovation Center employees left the company shortly thereafter.

\section{$9 \quad$ IBM's Culture Today}

Today, when viewed from the perspective of the OCI [10], IBM's culture has become more southleaning. Factors like security needs have superseded the need for job satisfaction, typical of a Defender organization. Because IBM now manages by plan, defensive, self-protective behaviors have become more evident. Dependence has resulted from the hierarchically controlled and non-participative management style adopted recently. Managers are now less likely to take individual initiative in making decisions because of fear of negative consequences. IBM has reverted to its old conventional ways, in which conservatism is rewarded and bureaucracy rules. In this environment, innovation is suppressed and agility is compromised. The need for power has increased significantly in the organization and participative management has been replaced by top-down authority. Perfectionism has also increased. Managers are afraid to make mistakes, copy many people on their communications in an effort to maintain a paper trail and they work long hours to attain narrowly defined objectives. Overall, IBM runs the risk of becoming too inwardly focused, a condition that almost led to its demise in the early 1990s.

When compared against the Innovation Center's OCI in [10, table 2], it is easy to see that the two organizations moved so far out of alignment that there was no way the Innovation Centers could survive in the new environment if they could not adapt their culture.

Table 1. Cultural fit between IBM and e-Business Innovation Centers prior to 1999.

\begin{tabular}{|c|c|c|}
\hline $\begin{array}{l}\text { Organizational } \\
\text { Characteristics }\end{array}$ & IBM & e-Business Innovation Centers \\
\hline Organizational Structure & Divisional & - $\quad$ Separate division \\
\hline \multirow[t]{2}{*}{ Product-Market Strategy } & Broad, changing product line & $\begin{array}{ll}\text { - } & \text { Best practices } \\
\text { - } & \text { e-Business leader } \\
\text { - } & \text { Thought leadership } \\
\text { - } & \text { Cutting edge technology }\end{array}$ \\
\hline & $\begin{array}{l}\text { Product innovation } \\
\text { Market responsiveness }\end{array}$ & $\begin{array}{ll}\text { - } & \text { Innovative solutions } \\
\text { - } & \text { Leading edge products } \\
\text { - } & \text { Customer driven } \\
\text { - } & \text { Customer demos } \\
\text { - } & \text { Futuristic } \\
\text { - } & \text { Collaborative } \\
\text { - } & \text { Strategic partnerships }\end{array}$ \\
\hline $\mathrm{R} \& \mathrm{D}$ & $\begin{array}{l}\text { Product design } \\
\text { Market research }\end{array}$ & $\begin{array}{ll}\text { - } & \text { Solution design } \\
\text { - } & \text { Constant market research } \\
\text { - } & \text { Money was no object } \\
\end{array}$ \\
\hline Production & $\begin{array}{l}\text { Flexible, adaptive equipment and } \\
\text { processes }\end{array}$ & $\begin{array}{ll}\text { - } & \text { Very flexible } \\
\text { - } & \text { Best equipment } \\
\text { - } & \text { Customer highly involved } \\
\text { - } & \text { Constantly monitored the market }\end{array}$ \\
\hline Control Processes & $\begin{array}{l}\text { Decentralized } \\
\text { Manage by performance }\end{array}$ & $\begin{array}{ll}\text { - } & \text { Manage by performance } \\
\text { - } & \text { Rewards, recognition } \\
\text { - } & \text { Highly motivational } \\
\end{array}$ \\
\hline Planning Processes & Act - Evaluate - Plan & - Act - Evaluate - Plan \\
\hline
\end{tabular}

Table 2. Cultural fit between IBM and e-Business Innovation Centers after 1999. 


\begin{tabular}{|c|c|c|}
\hline $\begin{array}{l}\text { Organizational } \\
\text { Characteristics }\end{array}$ & IBM & $\begin{array}{l}\text { e-Business Innovation } \\
\text { Centers }\end{array}$ \\
\hline Organizational Structure & - $\quad$ Divisional, but centralized & - $\quad$ Merged \\
\hline \multirow[t]{2}{*}{ Product-Market Strategy } & $\begin{array}{l}\text { - Re-evaluation of strategy } \\
\text { - Narrow, static product line } \\
\text { - Cut offerings based on } \\
\text { profitability }\end{array}$ & $\begin{array}{l}\text { - } \text { Best practices } \\
\text { - } \quad \text { e-business leader } \\
\text { - Thought leadership } \\
\text { - Cutting edge } \\
\text { technology }\end{array}$ \\
\hline & $\begin{array}{l}\text { - Innovative programs } \\
\text { eliminated } \\
\text { - Many reductions in force } \\
\text { - Responsiveness only to } \\
\text { market demands }\end{array}$ & $\begin{array}{ll}\text { - } & \text { Innovative solutions } \\
\text { - } & \text { Leading edge products } \\
\text { - } & \text { Customer driven } \\
\text { - } & \text { Customer demos } \\
\text { - } & \text { Futuristic } \\
\text { - } & \text { Collaborative } \\
\text { - } & \text { Strategic partnerships } \\
\end{array}$ \\
\hline $\mathrm{R} \& \mathrm{D}$ & $\begin{array}{ll}\text { - } & \text { Budgets cut } \\
\text { - } & \text { Layoffs } \\
\text { - } & \text { Minimal market research }\end{array}$ & $\begin{array}{l}\text { - Solution design } \\
\text { - } \quad \text { Constant market } \\
\text { research } \\
\text { - } \quad \text { Money was no object }\end{array}$ \\
\hline Production & $\begin{array}{l}\text { - } \text { Plant closings } \\
\text { - Divisions eliminated } \\
\text { - Unreliable production } \\
\text { - Lost contracts through } \\
\text { inability to deliver }\end{array}$ & $\begin{array}{l}\text { - } \text { Very flexible } \\
\text { - } \text { Best equipment } \\
\text { - } \text { Customer highly } \\
\text { involved } \\
\text { - Constantly monitored } \\
\text { the market }\end{array}$ \\
\hline Control Processes & $\begin{array}{l}\text { - } \text { Centralization } \\
\text { - Manage by plan } \\
\text { - Higher targets } \\
\text { - Emphasis on cost cutting }\end{array}$ & $\begin{array}{ll}\text { - } & \text { Manage by performance } \\
\text { - } & \text { Rewards, recognition } \\
\text { - } & \text { Highly motivational } \\
\end{array}$ \\
\hline Planning Processes & - $\quad$ Plan - Act - Evaluate & - $\quad$ Act - Evaluate - Plan \\
\hline
\end{tabular}

\section{Summary}

In the final analysis, a strong cultural fit between an organization and its environment is a key determinant in the success of a firm [15]. The initial fit between the Innovation Centers, IBM and the external environment was strong. IBM and the Innovation Centers were Prospectors, they shared similar values and their strategies were aligned with the external environment. When the external environment changed, IBM changed its strategy to that of a Defender. Continued success in this environment required the Innovation Centers to be more flexible and also act like Defenders. But since this counter cultural change was being imposed upon them by IBM, they found it difficult to adopt. This contributed to a lack of fit between the Centers and IBM, which in the end led to their demise. Perhaps the Innovation Centers were a flock of wild ducks that should never have been tamed.

\section{References}

1. Katholieke Universiteit Leuven, Available:

https://feb.kuleuven.be/eng/tew/academic/persbel/research/corporate_entrepreneurship.htm

2. Investopedia LLC., Available: http://www.investopedia.com/terms/c/corporate-culture.asp

3. Entreprenuer, Available: http://www.entrepreneur.com/encyclopedia/corporate-culture

4. Louis V. Gerstner, "The Culture Ate Our Corporate Reputation." Wall Street Journal, 2 Oct. 2016, p. A15.

5. David A. Garvin and Lynne C. Levesque. "Meeting the challenge of corporate entrepreneurship." Harvard

Business Review, vol. 84. no. 10, pp. 102-12 
6. Sandeep Vij and Jhanji Hitesh. "Business Incubation: A Review of Research Orientations, Impacts and Determinants of Success." Proceedings of the Tenth Biennial Conference on Entrepreneurship, EDI Ahmadabad. 2013.

7. Hackett, Sean M., and David M. Dilts. "A systematic review of business incubation research." The Journal of Technology Transfer, vol. 29, no. 1, pp. 55-82.

8. David A. Garvin and Lynne C. Levesque. "Meeting the challenge of corporate entrepreneurship." Harvard Business Review, vol. 84. no. 10, pp. 102-12.

9. Robert A. Cook, and J. Clayton Lafferty. "Organizational Culture Inventory." Human Synergistics International.,Available:

http://www.humansynergistics.com/productsservices/OrganizationDevelopment/OrganizationalCultureInventory

10.Koen Dittrich, Geert Duysters, and Ard-Pieter de Man. "Strategic repositioning by means of alliance networks: The case of IBM." Research Policy, vol. 36, no.10, pp. 1496-1511.

11.Sager, Ira. "Inside IBM: Internet Business Machines.", Bloomberg Business Week, Available: http://www.bloomberg.com/news/articles/1999-12-12/inside-ibm-internet-business-machines

12.E. Clampet, "IBM Opens E-Business Centers." Ecommerce Daily, November 15, 1999.

13.IBM Archives. "Chronological History of IBM." International Busniness Machines, Available: http://www03.ibm.com/ibm/history/history/year_1998.html.

14.Steve Lohr,. "Gerstner to step down as IBM Chief in March." New York Times, January 30, 2002.

15.Raymond E. Miles, and Charles C. Snow. "Fit, failure, and the hall of fame: How companies succeed or fail." New York: Free Press. Miller, CC, \& Cardinal, LB, 1994. Strategic planning and firm performance: A synthesis of more than two decades of research. The Academy of Management Journal vol. 37 no.6, 1994, pp. 1649-1665. 